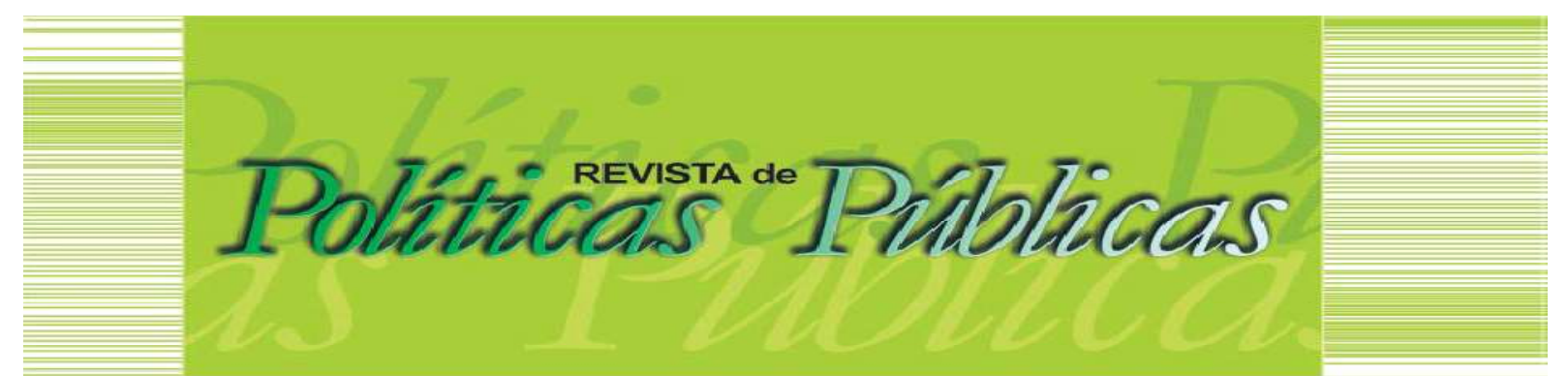

\title{
A EDUCAÇÃO DO CAMPO E O FIM DAS POLÍTICAS PÚBLICAS COMO AS CONHECEMOS: questões para reflexões de futuro
}

Clarice Aparecida Santos ${ }^{1}$

\section{Resumo}

O presente ensaio propõe-se a analisar a Educação do Campo no seu triplo signo - Campo - Educação - Políticas Públicas, com ênfase no processo de institucionalização de políticas públicas num contexto histórico de abertura na construção da democracia como regime que institui direitos, em relação ao contexto atual de regressividade nas políticas educacionais. 0 projeto de empresariamento da educação em todos os níveis impõe um conjunto de medidas visando 0 encolhimento dos espaços de luta dos/as trabalhadores/as, especialmente dos 3camponeses, indígenas e quilombolas e elimina os mecanismos garantidores das condições de acesso e permanência ao ensino público e gratuito por estas populações. Apresenta ainda um conjunto de questões para reflexão dos/as educadores/as e movimentos sociais populares na perspectiva da resistência ativa e ampliação do espaço público.

Palavras-chave: Educação do Campo. Políticas públicas. Empresariamento. Resistência.

FIELD EDUCATION AND THE END OF PUBLIC POLICIES AS WE KNOW IT: questions for future reflections

\begin{abstract}
This essay proposes to analyze Field Education in its triple sign - Field - Education - Public Policies, with emphasis on the process of institutionalization of public policies in a historical context of openness in the construction of democracy as a regime that establishes rights, in relation to the current context of regressivity in educational policies. The project of entrepreneurship of education at all levels imposes a set of measures aimed at shrinking the spaces of struggle ofworkers, especiallypeasants, indigenous and quilombolas and eliminates the mechanisms guaranteeing the conditions of access and permanence to public education and free by these populations. It also presents a set of questions for the reflection of educators and popular social movements in the perspective of active resistance and expansion of the public space.
\end{abstract}

Keywords: Field Education. Public policies. Entrepreneurship. Resistance.

Artigo recebido em: 18/06/2019 Aprovado em: 24/10/2019

DOI: http://dx.doi.org/10.18764/2178-2865.v23n2p501-513.

1 Pedagoga. Doutora em Políticas Públicas e Formação Humana. Docente do ensino superior da Universidade de Brasília.

E-mail: claricesantos61@gmail.com 


\title{
1 INTRODUÇÃO
}

\author{
A injustiça avança hoje a passo firme \\ Os tiranos fazem planos para dez mil anos \\ O poder apregoa: as coisas continuarão a ser como são \\ Nenhuma voz além da dos que mandam \\ E em todos os mercados proclama a exploração; \\ isto é apenas o mau começo. [...] \\ (Brecht,B. Elogio da Dialética)
}

A Educação do Campo, no Brasil, nasceu sob um triplo signo: o signo da educação, o signo do campo e o signo da política pública. Esse triplo signo é quem dá o significado teórico e histórico da Educação do Campo (CALDART, 2012), que celebrou 20 anos no Brasil em 2018.

Por eles e com eles estruturou-se um conjunto complexo de ações que tomaram o tempo e atenção do tripé sobre a qual se organizou e se desenvolveu em razão do triplo signo: os movimentos sociais e sindicais populares, os/as docentes das universidades e escolas públicas e os órgãos governamentais em todas as esferas.

Este conjunto complexo envolve as lutas pelo direito à educação das populações que vivem e trabalham no campo, a elaboração teórica que embasa o projeto político-pedagógico da Educação do Campo, assim como as políticas públicas conquistadas, notadamente o Programa Nacional de Educação na Reforma Agrária - PRONERA e as Licenciaturas em Educação do Campo.

É impossível tratá-las separadamente. As reflexões aqui apresentadas têm as políticas públicas como eixo e sempre estarão ladeadas pelas concepções e projeto histórico de campo e de educação.

O movimento da Educação do Campo nestes 20 anos foi embalado por duas premissas fundamentais apreendidas de Marilena Chauí e Francisco de Oliveira, respectivamente: (i) A instituição de direitos é da natureza dos regimes democráticos (CHAUÍ, 2002); (ii) As políticas públicas consistem no movimento de ampliar os espaços públicos e restringir os limites do privado, na esfera pública (OLIVEIRA, 2001).

Com base nessas premissas, legitimaram-se as lutas dos/as camponeses/as pelo direito à educação de acordo com seus interesses e suas necessidades. De igual modo, elas foram institucionalizadas quando o Estado as reconheceu, por meio de um conjunto de instrumentos e normas no âmbito do ordenamento jurídico do Estado, no momento em que a sociedade brasileira avançou na sua consciência cidadã e, também, quando as populações historicamente alijadas do processo de desenvolvimento como Nação enxergaram, neste movimento, a oportunidade de avançar nas suas reivindicações. 


\section{A EDUCAÇÃO DO CAMPO E O FIM DAS POLIITICAS PÚBLICAS COMO AS CONHECEMOS: questões para reflexões de futuro}

O pacto político nacional, representativo do momento daquela consciência e materializado na Constituição de 1988, instituiu, no seu artigo 205, a educação como "direito de todos, dever do Estado, da família e da sociedade". Nesse sentido, os movimentos sociais e sindicais populares do campo, representativos de uma parcela da população do campo, interpretaram o significado dessa cláusula como abertura da esfera pública para posicionar-se no cenário político com a força de uma exigência historicamente não reconhecida: 0 direito à educação como direito de todos os que vivem no campo, na sua diversidade tendo como dever do Estado assegurar o seu cumprimento.

A história veio a corroborar o acerto dessa estratégia quando o Conselho Nacional de Educação (CNE), por meio da Câmara de Educação Básica (CEB), após longo processo de diálogo e audiência, publicou a Resolução CNE/CEB n. ${ }^{\circ}$ 01, de 3 de abril de 2002, instituindo as "Diretrizes Operacionais para a Educação Básica nas escolas do campo" (MEC, 2013). Seguiu-se, a partir daí, um longo processo de debates no âmbito federal, estadual e municipal promovido pela legitimidade das reivindicações das organizações de trabalhadores/as do campo na área da educação.

O PRONERA, instituído no ano de 1998 por meio da Portaria MEPF n. ${ }^{0}$ 10, de 16 de abril de 1998 no Instituto Nacional de Colonização e Reforma Agrária (INCRA), originou-se como resultado de um amplo processo de mobilização de massa dos trabalhadores rurais sem terra apoiados por um conjunto significativo de apoiadores como o Conselho dos Reitores das Universidades Brasileiras (CRUB), Fundação das Nações Unidas para a Infância (UNICEF), Fundação das Nações Unidas para a Ciência e a Cultura (UNESCO) e Conferência Nacional dos Bispos do Brasil (CNBB) (SANTOS, 2012).

O PRONERA e a Resolução CNE/CEB n. ${ }^{0}$ 01/2002 foram fundamentais para o avanço no campo das políticas públicas em âmbito federal e pavimentaram a construção de um amplo Programa de formação de educadores para as escolas do campo, conhecido como Procampo - Licenciaturas em Educação do Campo.

O PRONERA, de acordo com pesquisa financiada pelo INCRA e executada pelo Instituto de Pesquisas Econômicas Aplicadas (IPEA) e publicada no ano de 2015, denominada II Pesquisa Nacional sobre Educação nas Áreas de Reforma Agrária - II PNERA (IPEA, 2015), formou cerca de 200 mil pessoas dos assentamentos rurais do país do nível fundamental ao nível de Especialização, nas áreas de Pedagogia, Agronomia, Geografia, História, Medicina Veterinária e Direito. Com um orçamento significativo nos governos Lula e Dilma, o PRONERA chegou a dispor de orçamento anual da ordem de $\mathrm{R} \$ 70$ milhões de reais.

Os Cursos de Licenciatura em Educação do Campo, neste ano de 2019, estão instituídos em 31 Universidades e Institutos Federais e cerca de 7 mil estudantes compõem o corpo discente destes Cursos em regime de alternância dos tempos de estudo. 
A potência educativa e organizativa desta experiência histórica levou o Governo Lula a assinar e publicar em 2010 o Decreto Presidencial n. ${ }^{0}$ 7.352/2010, que

\begin{abstract}
Dispõe sobre a política de educação do campo e o Programa Nacional de Educação na Reforma Agrária - PRONERA", consolidando a Educação do Campo como política pública e reconhecendo os homens e mulheres, jovens, crianças e adolescentes que vivem no campo - os agricultores familiares, os extrativistas, os pescadores artesanais, os ribeirinhos, os assentados e acampados da reforma agrária,os trabalhadores assalariados rurais, os quilombolas, os caiçaras, os povos da floresta, os caboclos e outros que produzam suas condições materiais de existência a partir do trabalho no meio rural, como sujeitos do direito à educação. Determinou que a política de Educação do Campo deve se comprometer com a "ampliação e qualificação da oferta de educação básica e superior às populações do campo, e será desenvol1vida pela União em regime de colaboração com os Estados, o Distrito Federal e os Municípios, de acordo com as diretrizes e metas estabelecidas no Plano Nacional de Educação[...]. (BRASIL, 2010).
\end{abstract}

Os determinantes políticos que conduziram o País ao golpe midiático-jurídico-parlamentar em 2016 e à eleição de Jair Bolsonaro, em 2018, alteraram definitivamente as condições políticas objetivas e subjetivas que deram origem e sustentaram as políticas de Educação do Campo nos 20 anos e já comprometem sua continuidade. A natureza da regressividade imposta no curto período entre 2016 e 2019 permite afirmar tratar-se de uma estratégia de fenecimento das políticas públicas.

\title{
2 A EDUCAÇÃO DO CAMPO E O FIM DAS POLÍTICAS PÚBLICAS
}

[...],mas entre os oprimidos muitos há que agora dizem Aquilo que nós queremos nunca mais o alcançaremos! [...]

(BRECHT, Bertolt. Elogio da Dialética)

Reunidos na Universidade de Brasília por ocasião do Encontro Nacional 20 anos da Educação do Campo e do PRONERA em junho de 2018, cerca de mil participantes entre camponeses/as, lideranças dos movimentos sociais e sindicais populares, educadores/as das escolas do campo, Universidades e Institutos Federais de todo o País afirmaram em Manifesto que a crise estrutural da sociedade brasileira, com o aprofundamento do golpe midiático-jurídico-parlamentar deflagrado em 2016 expôs o acirramento dos conflitos de classe ao dirigir a maior parte da economia para o capital estrangeiro.

O Manifesto confirma tais afirmações quando diz que

As medidas econômicas liberais adotadas pelo governo atual ratificam estas afirmações, como: a Emenda Constitucional $n^{\circ} 95$, que congela os investimentos totais do País para assegurar os lucros ao capital financeiro; a entrega do Pré-Sal aos grandes conglomerados transnacionais, aliado à abertura do capital da Petrobras para o setor privado, causa principal da crise dos combustíveis; a Reforma Trabalhista e os ataques à Previdência Pública; os cortes orçamentários, contingenciamentos e criminalização das ações das/os docentes, gestoras/es e das próprias Universidades e Institutos Federais, colocando em risco a 


\title{
A EDUCAÇÃO DO CAMPO E O FIM DAS POLIITICAS PÚBLICAS COMO AS CONHECEMOS: questões para reflexões de futuro
}

autonomia universitária; a ofensiva da Escola sem Partido; a militarização das escolas; a criminalização das ações dos Movimentos Sociais Populares e Sindicais; e a judicialização dos projetos desenvolvidos com estes sujeitos coletivos (FONEC, 2018, p.1).

No plano da educação, houve apreensão em torno das iniciativas governamentais na perspectiva de ampliação dos interesses e negócios privados sobre a educação pública.

\begin{abstract}
A educação tem sido uma área prioritária para expansão dos interesses do capital em nosso país e tal condição tem mobilizado o governo a alterações significativas na legislação em favor de tais interesses. Não à toa, a primeira medida pós-golpe foi a reforma do Ensino Médio que revela uma estratégia articulada e realizada no contexto de um Golpe para impor à sociedade um novo modelo - curricular e de gestão escolar, abrindo espaço para a entrada solene e formal das empresas e suas organizações na disputa pelo FUNDEB, que movimenta um orçamento anual de mais de 130 bilhões de reais (FONEC, 2018, p.1)
\end{abstract}

No tocante à população do campo, as medidas citadas repercutem gravemente sobre as condições de acesso e permanência à educação básica num contexto já agravado cujo índice médio é de $20 \%$ de analfabetos/as, a escolaridade média é de apenas 4,5 anos de escolarização e 0 fechamento de escolas do campo nos estados e municípios é um processo em escala ascendente, mesmo no (curto) período de abertura do Estado às exigências populares.

\subsection{0 processo de aniquilamento das políticas públicas por uma "nova" política educacional}

Compreender o processo político atual e seus propósitos acerca do futuro das políticas educacionais torna-se possível graças a um conjunto de axiomas que podem ser resumidos no conceito de empresariamento da educação. Daí derivam todos os componentes de qualquer análise rigorosa sobre os atos político-administrativos do governo Bolsonaro.

De acordo com Freitas (2018), são eles:

a) O livre mercado, segundo o qual sua própria lógica produz a qualidade por meio da concorrência;

b) 0 empreendedorismo como lógica de organização do ensino e da gestão, tendo como modelo as empresas;

c) A má gestão do Estado e, portanto, a necessidade da redução de sua atuação já que eficiência e qualidade serão asseguradas pela concorrência do livre mercado.

As primeiras medidas adotadas pelo governo em 2019 e que incidem diretamente sobre as políticas de Educação do Campo revelam-se alinhadas a tais axiomas, a saber: 
(i) O desmonte da Secretaria de Educação Continuada, Alfabetização e Diversidade SECADI e sua renomeação para Secretaria de Modalidades Especiais - SEMESP. Ao excluir o termo "Diversidade" demonstra-se, por um lado, o desprezo dos novos donos do poder pelo respeito e pelo reconhecimento de uma diversidade conquistada pelos povos originários, tradicionais e do campo e, por outro lado, o atendimento dos interesses do capital na educação, a quem a eliminação de todo e qualquer direito reduz os custos operacionais da "empresa" educacional, reduzindo demandas orçamentárias e liberando orçamento para o cumprimento dos compromissos da dívida pública com o capital;

(ii) Os cortes orçamentários como decorrência imediata da imposição da Emenda Constitucional 95 desmontam os mecanismos de financiamento público às instituições públicas e força o Estado à inserção das empresas na oferta de educação básica e superior, seja por meio das instituições privadas financiadas com mecanismos de financiamento público (ampliação de bolsas ou mesmo o sistema de vouchers para a educação básica) ou mesmo por meio do sistema público, com a redução da oferta por meio de instituições públicas com gestão pública, tal como os conhecemos.

Os efeitos imediatos dos cortes sobre a Educação do Campo já compõem dados da realidade. O PRONERA teve sua atuação paralisada, cujas perspectivas de financiamento reduziramse à quitação de parcelas de pagamento aos cursos em vigência, sem perspectiva de implementação de nenhum dos mais de cem projetos já aprovados aguardando serem efetivados.

A redução do número de bolsas-permanência para os estudantes de Licenciatura em Educação do Campo justificadas como "medidas administrativas", além dos cortes no orçamento das Universidades e Institutos Federais terão efeito devastador, uma vez que a alternância nos tempos de estudo demanda recursos para alojamento e alimentação no Tempo Universidade.Sem estas condições, haverá um esvaziamento crescente no número de estudantes, criando-se as condições para a extinção dos Cursos.

(iii) Os mecanismos antidemocráticos instituídos por meio de decretos presidenciais visam impedir a participação popular considerada "ideologizada", impondo limites à possibilidade de ampliação dos espaços públicos na esfera pública e funciona como mecanismo de blindagem à intervenção social. A extinção dos Conselhos e Comissões está entre os mecanismos criados nas últimas décadas e reconhecidos para atender a requisitos (inclusive liberais) nas políticas públicas. Nesse sentido, o binômio eficiência/efetividade constitui um destes mecanismos.

A intervenção indevida nas Universidades Federais mediante o decreto que altera as normas de nomeação dos/as dirigentes de ensino superior, além da cassação do direito de os/as dirigentes nomearem por livre decisão os pró-reitores,constituem outros mecanismos de natureza 


\section{A EDUCAÇÃO DO CAMPO E O FIM DAS POLÍTICAS PÚBLICAS COMO AS CONHECEMOS: questões para reflexões de futuro}

antidemocrática que têm 0 objetivo de fechar as portas para toda e qualquer possibilidade de resistência das instituições públicas.

(iv) $O$ aparente silenciamento dos liberais a tais medidas é revelador da sua própria estratégia de implementação do projeto do capital na educação. À medida que são reduzidos os instrumentos públicos de financiamento às instituições do Estado, alargam-se as possibilidades de hegemonização do capital e de seu projeto na educação, por meios os mais diversos, tal como já citados anteriormente.

Ademais, essas medidas, no âmbito federal, caminham a passos largos por iniciativa de entes federados - estados e municípios, projetos com a marca da volatilidade, típica do capital. Entre elas, a eliminação dos concursos públicos e a introdução de plataformas digitais para contratação de professores/as; o compartilhamento da gestão das escolas com empresas, aquisição de material didático e pedagógico das empresas, entre outras. Para adaptarem aos "novos" tempos dos mecanismos do capital dentro do sistema público tal como nunca visto, os/as professores/as têm sido obrigados/as a submeterem-se a treinamentos e cursos de capacitação operados pelas próprias empresas dentro das escolas.

Todas essas medidas no seu conjunto impactam sobre a Educação do Campo e seu triplo signo, uma vez que restringem a participação dos/as sujeitos/as do campo no processo de elaboração, execução e avaliação de políticas públicas de seu interesse e restringem a participação dos/as sujeitos do campo na elaboração do projeto educativo que lhes assegurem as condições de se desenvolverem plena e potencialmente como construtores de seu próprio futuro. Por fim, restringem as condições de resistência a esse processo, as condições de pensarem e planejarem seu futuro com direitos, no campo, de produzir os meios de vida de outras formas, antagônicas às formas capitalistas.

\subsection{O legado político - pedagógico - organizativo dos 20 anos da Educação do Campo para as políticas públicas}

Construiu-se uma consciência coletiva no âmbito dos movimentos sociais e sindicais populares e nas instituições de ensino, relativo tanto ao patrimônio político-organizativo quanto ao arcabouço teórico-pedagógico, acumulados pela Educação do Campo no Brasil nos seus 20 anos.

Os coletivos organizados nos estados e municípios país afora num conjunto de Fóruns, Articulações, entre outras denominações que se dão à organização dos atores sociais em luta e em movimento, fazem parte do patrimônio político-organizativo, além das variadas iniciativas de Encontros, Seminários, em espaços os mais diversos de análise, reflexão, compartilhamento de conhecimentos e 
experiências.É distintivo deste movimento, a interação entre os/as camponeses/as e suas organizações e os intelectuais, com o fim de avançar na resistência do construído e avançar sobre o que ainda não foi conquistado.

Espaços acadêmicos da Educação do Campo foram instituídos nas Universidades, como linhas de pesquisa em Mestrados e doutorados, grupos de pesquisa, centros multi e transdisciplinares agregam ao tema da Educação do Campo grandes questões da contemporaneidade como as questões de gênero, raça, identidade e orientação sexual que tensionam a todo momento as categorias teóricas e metodológicas. Tais centros atuam na perspectiva da indissociabilidade entre método políticopedagógico e método político-organizativo e estabelecem a ponte entre conhecer e fazer, conhecer e resolver. Isso constitui um legado de um tempo de acúmulo teórico-pedagógico para os tempos futuros.

Desse legado, destacam-se a produção acadêmica gerada pelos próprios camponeses/as em processos de estudos e pesquisas em nível de graduação e pós-graduação ou ainda por outros pesquisadores/as. A II PNERA apontou que o PRONERA resultou em 5.920 produções acadêmicocientíficas. Foram 2.747 Monografias/Trabalhos de Conclusão de Curso, 180 artigos científicos e 136 livros. O PRONERA passou a ser objeto de estudos acadêmico-científicos, registrando a existência, por exemplo, de 260 dissertações, 63 teses, 51 livros e 469 artigos científicos sobre o Programa.

Assim, seria inevitável que um processo longo e marcado por permanentes tensões com 0 Estado nas suas mais diversas representações tivesse produzido igualmente contradições de toda ordem. O capital, como afirma Mészáros (2002.p.96), atua o tempo inteiro a partir da lógica sociometabólica, no sentido de tudo transformar em mercadoria, em produtos a serviço de sua própria reprodução.

O capital disputa a Educação do Campo com o polo do trabalho no seu conceito originário pela sua ressignificação, na estratégia de esvaziá-lo de sua natureza de classe e tensiona o Estado pela sua lógica. Programas, projetos, materiais didáticos, publicações as mais diversas são conhecidas na perspectiva da educação no campo, do empreendedorismo, do Agro'.

Para a Educação do Campo, o legado construído

[...] ainda que com imensas limitações, significam a conquista de fundos públicos para a garantia do direito à educação dos trabalhadores. Nossas práticas educativas compreendem a imprescindivel necessidade de superação da sociabilidade gerada pela sociedade capitalista, cujo fundamento organizacional é a exploração do ser humano sob todas asformas, a geração incessante de lucro e a extração permanente de mais-valia. Ao contrário desta perspectiva, nossas práticas educativas têm como horizonte formativo 0 cultivo de uma nova sociabilidade, na qual o fundamento encontra-se pautado na superação da forma capitalista de organização do trabalho, na associação livre das/os trabalhadoras/es, na solidariedade e na justa distribuição social da riqueza construída coletivamente pelos seres humanos (FONEC, 2019, p. 2). 


\title{
A EDUCAÇÃO DO CAMPO E O FIM DAS POLÍTICAS PÚBLICAS COMO AS CONHECEMOS: questões para reflexões de futuro
}

Pode-se afirmar, portanto, que se construiu no Brasil uma materialidade, uma base política no campo da educação, que vem dos processos organizativos e de um projeto contra- hegemônico de campo, desde as lutas sociais empreendidas nas últimas décadas. Uma materialidade que estruturou não somente uma base teórica, mas também formou uma base técnica objetiva em todos os campos do conhecimento sobre a qual erige um movimento sólido de Educação do Campo. Sua robustez se assenta sobre os movimentos sociais e sindicais populares e seu projeto, que já demonstram serem capazes de desenvolver novas formas de produção da vida, de relação com a terra e com a natureza, de novas sociabilidades.

\section{QUESTÕES PARA PROVOCAR REFLEXÕES NO FUTURO}

\author{
[...] Quem ainda está vivo não diga: nunca! \\ O que é seguro não é seguro. \\ As coisas não continuarão a ser como são. \\ Depois de falarem os dominantes \\ Falarão os dominados \\ Quem pois ousa dizer: nunca? \\ De quem depende que a opressão prossiga? De nós. \\ De quem depende que ela acabe? Também de nós. \\ O que é esmagado que se levante! \\ O que está perdido, lute! \\ O que sabe ao que se chegou, que há aí algo que o retenha, liberte-se! \\ E nunca será: ainda hoje. \\ Porque os vencidos de hoje são os vencedores de amanhã.
}

(BRECHT, Bertolt. Elogio da Dialética)

Será esta materialidade objetiva capaz de resistir aos desafios do tempo atual? Ainda há espaços para avanços, no ambiente das políticas públicas? Como se organiza e com quem se organiza a resistência ativa?

Os primeiros 20 anos constituíram tempo de afirmação das marcas da Educação do Campo: a luta pelo direito à educação e, consequentemente, a luta por escola pública no campo, além da formação de educadores e do projeto pedagógico. Os cursos do PRONERA e de Licenciatura em Educação do Campo foram os laboratórios fecundos desta nova condição.

A resistência ativa e coletiva é a condição para a afirmação do legado histórico, sem a qual não subsistirá, assim como nenhuma obra coletiva no campo dos direitos subsistirá pela mera afirmação de seus feitos.

A Educação do Campo se insere como particularidade na totalidade dos processos de avanços dos direitos das populações historicamente expulsas do projeto hegemônico do capital no campo da educação. A Associação Nacional dos Dirigentes das Instituições Federais de Ensino 
Superior - ANDIFES publicou resultados da V Pesquisa do Perfil Socioeconômico dos Estudantes de Graduação das Universidades Federais. De acordo com o estudo, "o perfil dos estudantes de graduação das universidades federais brasileiras está, a cada edição, mais próximo do perfil sociodemográfico do Brasil. Os resultados mostram que as universidades expressam a diversidade cultural, racial e de sexo da população brasileira, assim como a desigualdade de renda".

Algumas questões e desafios estão postas à mesa das reflexões profundas para a Educação do Campo e não estão desvinculadas das reflexões gerais da classe trabalhadora acerca do processo regressivo que caracteriza a atual fase das políticas públicas educacionais, no Brasil. São elas:

(i) Conhecer mais e melhor o projeto neoliberal que se desdobra no projeto de empresariamento da educação em todas as suas nuances, seus métodos e seus efeitos que já se vislumbram na realidade de estados e municípios. Interpretar as iniciativas supostamente virtuosas para "salvar a educação", destruindo o sistema público. Como nos alerta FREITAS (2018, op.cit), é necessário rejeitar a tese de que, sob 0 argumento de que o sistema público de ensino tem problemas, deva ser substituído pelo modelo privado, empresarial. As empresas educacionais transformaram-se em conglomerados transnacionais de propriedade de fundos privados com ações nas Bolsas de Valores, cujo único objetivo é o lucro, e cujo método é a competição;

(ii) Reativar o papel da crítica permanente e qualificação de nossos conceitos. 0 debate acerca do conceito de "qualidade da educação" deve ser expandido às/aos educadoras/es em processo de formação, seja inicial ou continuada, mas também aos pais, mães, comunidades em geral. 0 elementar requisito de qualidade da educação no Brasil está inscrito na Constituição Federal e diz respeito a que a escola pública e gratuita é um direito de todos, sem restrições. As políticas públicas implementadas no intuito de tratar "desigualmente os desiguais" - negros, indígenas, quilombolas e campo - são mecanismos garantidores de igualdade social no acesso à educação e não podem ser substituídos por um modelo uniforme com base em testes e provas sobre a aprendizagem formal das disciplinas básicas - português e matemática. Há conhecimento nos modos de produção e reprodução da vida e aprendizagem fora dos espaços restritos da escola que devem ser reconhecidos e estes não se encaixam no sistema restrito de medição de conhecimento; 


\section{A EDUCAÇÃO DO CAMPO E O FIM DAS POLÍTICAS PÚBLICAS COMO AS CONHECEMOS: questões para reflexões de futuro}

(iii) Ressignificar o papel da pesquisa educacional. A implementação de políticas neoliberais no âmbito dos estados e municípios deve ser estudada e acompanhada pelas Universidades e deve compor os planos de ensino, pesquisa e extensão dessas instituições, com participação ativa das comunidades. Exige ainda a busca de elementos e experiências de outros países que já aplicaram os modelos neoliberais à educação e seus resultados na perspectiva da prometida "qualidade";

(iv) Investigar as contradições do polo do capital é um imperativo destes tempos. Analisar a contradição principal da ordem do capital inserida na educação por meio da competitividade entre estudantes e escolas, a educação voltada aos ditames da empregabilidade e do empreendedorismo. A quantos destes/as jovens, efetivamente se cumprem as promessas desse modelo? E àqueles que não se "ajustam" por razões inclusive de escolha? Quais perspectivas, se lhes são negadas as opções de escolha?;

(v) Recuperar o papel da escola pública e das Universidades como instituições educativas e formadoras da sociedade, para além do seu papel de ensinar e formar profissionais. Investigar os problemas, os temas e as questões potencialmente mobilizadores das comunidades onde estão inseridas e contribuir para sua compreensão, suas possibilidades e suas potencialidades na busca de respostas e soluções, de forma coletiva e soberana, contribuindo para a superação das marcas do populismo e do autoritarismo, característicos da formação social brasileira;

(vi) Retomar a capacidade de organizar as lutas sociais por transformações. As mudanças não são impossíveis, ainda que tudo indique o contrário. É possível reconstruir o processo de avanços nas políticas públicas. A correlação de forças do ano de 1998, quando foi instituído o PRONERA, se analisada de forma objetiva, indica pouca ou nenhuma possibilidade de avanço de qualquer natureza em direção às propostas oriundas das forças populares. Era primeiro ano do segundo mandato de Fernando Henrique Cardoso, eleito em primeiro turno. Porém, a correlação de forças foi alterada pela única razão pela qual se torna possível fazer a balança pender, ainda que contraditoriamente, para as causas do povo: as lutas sociais. 0 massacre de Eldorado dos Carajás, como reação violenta às lutas dos Sem Terra do Sudoeste do Pará colocou as forças da ordem em xeque, nacional e internacionalmente, e abriu-se uma fresta de luz no tempo sombrio, porque havia naquelas lutas um projeto de transformações do campo brasileiro, incluindo a educação que foi possível avançar; 
(viii) Sistematizar as práticas para potencializar o acúmulo político-organizativo e pedagógico das lutas por políticas públicas de educação desde as classes populares que vivem e trabalham no campo. No Brasil isso é tarefa imprescindível para projetar o futuro. As gerações do presente têm a aprender com as gerações passadas na sua determinação por fazer resplandecer a aurora dos/as trabalhadores/ as do campo;

Nesse sentido, as gerações que elaboraram e concretizaram os projetos educativos dos/as trabalhadores/as têm o dever de registrá-las como patrimônio de um tempo em que os circuitos da história estiveram abertos e as classes populares puderam experimentar, ainda que limitadamente, das promessas da democracia.

Por fim, em que pese a realidade e o contexto, impõe-se àqueles que lutam o dever de associar a disposição de resistência ativa à atitude de resiliência, acreditar no tempo e no patrimônio, no legado histórico vivo e em movimento. Fazê-lo florescer no chão da escola, de baixo para cima. Conjugar o verbo "esperançar", construindo o tempo futuro e atuando sem tréguas no tempo presente.

\section{REFERÊNCIAS}

ANDIFES. V Pesquisa do Perfil Socioeconômico dos Estudantes de Graduação das Universidades Federais . Disponível em: http://www.andifes.org.br/v-pesquisa-perfil-socioeconomico-dos-estudantesde-graduacao-das-universidades-federais/. Acesso em: 18 jun. 2019.

BRASIL. Dispõe sobre a política de educação do campo e o Programa Nacional de Educação na Reforma Agrária - PRONERA, 2010. Disponível em: http://www.planalto.gov.br/ccivil_03/_ato20072010/2010/decreto/d7352.htm. Acesso em 14 jun. 2019.

CALDART, Roseli Salete. Educação do Campo. In: CALDART, Roseli; PEREIRA, Isabel Brasil.; FRIGOTTO, Gaudêncio (org.). Dicionário de Educação do Campo. Rio de Janeiro, São Paulo: Escola Politécnica de Saúde Joaquim Venâncio, Expressão Popular, 2012.

CHAUÍ, Marilena. A sociedade democrática. In: JUNIOR, José Geraldo de Sousa; MOLINA, Monica Castagna; TOURINHO NETO, Francisco (org.). Introdução Crítica ao Direito Agrário. O Direito Achado na Rua. V.3. GTRA-DEX/FD/NEP/NED/Editora UnB. São Paulo: Imprensa Oficial do Estado de São Paulo, 2002.

FONEC. Carta-Manifesto 20 anos da Educação do Campo e do PRONERA. Brasília,DF: junho/2018.

Documento Final. Reunião Ampliada Nacional. Brasília, DF: abril/2019.

FREITAS, Luiz Carlos de. A reforma empresarial da educação: nova direita, velhas ideias. São

Paulo: Expressão Popular, 2018. 


\section{A EDUCAÇÃO DO CAMPO E O FIM DAS POLÍTICAS PÚBLICAS COMO AS \\ CONHECEMOS: questões para reflexões de futuro}

IPEA. II Pesquisa Nacional sobre Educação nas Áreas de Reforma Agrária - II PNERA . Disponível em: http://www.ipea.gov.br/portal/index.php?option=com_content\&view=article\&id=25640. Acesso em: 16 jun. $/ 2019$.

MEC. Diretrizes Operacionais para a Educação Básica nas escolas do campo . Disponível em:

http://portal.mec.gov.br/index.php?option=com docman\&view=download\&alias=13800-rceb001-02pdf\&category_slug=agosto-2013-pdf\&ltemid=30192. Acesso em: 14 jun. 2019.

MÉSZÁROS, I. Para além do capital. São Paulo: Boitempo, 2002.

OLIVEIRA, Francisco de. A nova hegemonia da burguesia no Brasil nos anos 1990 e os desafios de uma alternativa democrática. In: CIAVATTA, Maria; FRIGOTTO, Gaudêncio. Teoria e Educação no Labirinto do Capital. Petrópolis, RJ: Vozes, 2001.

SANTOS.C.A. Educação do Campo e Políticas Públicas no Brasil. Brasília: LiberLivro;Faculdade de Educação/Universidade de Brasília, 2012. p. 41-61.

\section{Notas}

${ }^{1}$ Agro citado aqui como um conceito totalizante de um projeto associado ao modelo do Agronegócio. 